\title{
Ventriculitis por Salmonella enteritidis
}

\section{Sr. Director:}

Presentamos el caso de una paciente de 47 años con poliangeítis microscópica de 8 años de evolución, en tratamiento con azatioprina y prednisona, que acude a urgencias por cefalea, náuseas y vómitos. Se diagnostica hemorragia subaracnoidea con mínima hemorragia intraventricular. La arteriografía descarta alteración vascular y se inicia tratamiento inmunosupresor con ciclofosfamida ante la sospecha de hemorragia secundaria a poliangeítis microscópica. A los 5 días presenta disminución del nivel de conciencia; se realiza tomografía computarizada (TC) en la que se observa hidrocefalia con dilatación biventricular. Se colocan dos drenajes ventriculares externos. A los 6 días de inicar el tratamiento inmunosupresor presenta fiebre elevada; se realizan cultivos de sangre y líquido cefalorraquídeo (LCR), siendo positivos para Salmonella enteritidis sensible a cefotaxima, tratamiento ya iniciado de forma empírica. Una semana después de iniciar el tratamiento, persiste Salmonella enteritidis en cultivos de LCR. Se retiran de forma escalonada los dos drenajes, cuyo cultivo fue positivo para Salmonella enteritidis al igual que el LCR obtenido. Se realiza una punción lumbar que evidencia: glucosa $35 \mathrm{mg} / \mathrm{dl}$, proteínas 9,3 g/l y 60.267 células por microlitro de predominio polimorfonuclear con cultivo bacteriológico negativo, mientras que el LCR del ventrículo presentó glucosa $5,1 \mathrm{mmol} / 1$, proteínas $2,3 \mathrm{~g} / 1$ y células 130/microlitro. Se realizó resonancia magnética de columna que descartó absceso epidural. La TC craneal de control tras la retirada de los drenajes evidencia un absceso cerebral frontal derecho y paraventricular posterior izquierdo (fig. 1). Se procede a drenaje por punción quirúrgica, dejando catéter de drenaje izquierdo para tratamiento intratecal con amikacina. Tras 10 días de tratamiento intratecal se decide la retirada del catéter intraventricular. Ante la persistencia de fiebre alta, se recoloca el drenaje ventricular externo izquierdo y se coloca un drenaje lumbar para la administración durante 10 días más de amikacina intratecal, lumbar y endovenosa, a pesar de que los cultivos son negativos, quedando afebril a las 48 horas.

La poliangeítis microscópica es una vasculitis necrotizante que afecta a vasos de pequeño calibre. Clínicamente se caracteriza por un cuadro inespecí- 


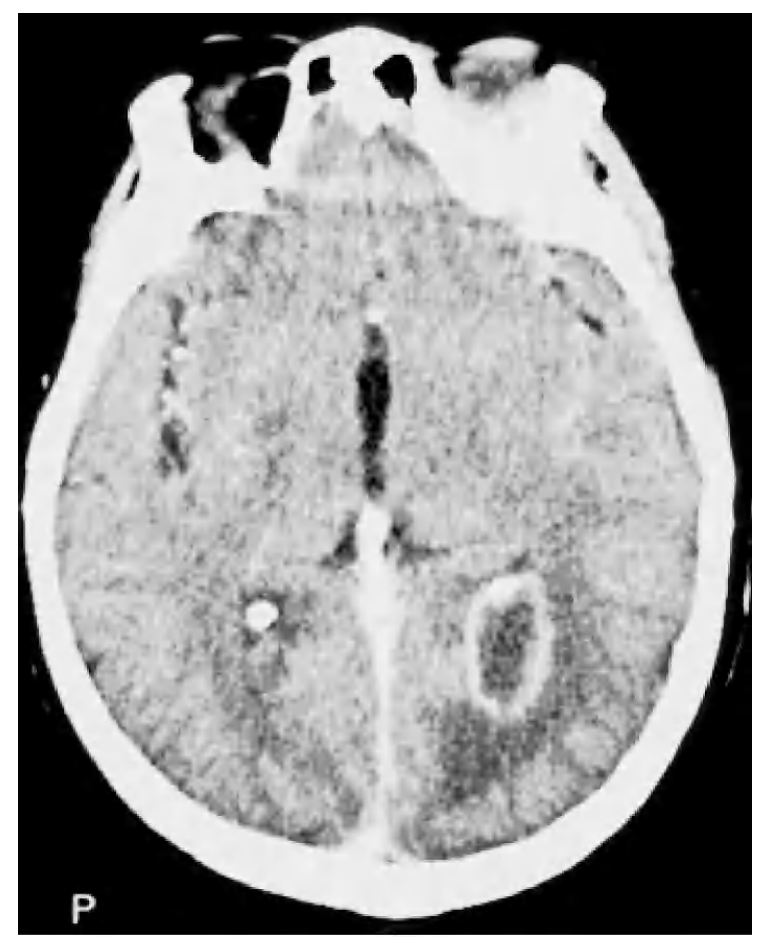

Figura 1. Absceso cerebral.

fico de fiebre, pérdida de peso y artromialgias. Es característica la afectación renal, como glomerulonefritis necrotizante asociada a capilaritis pulmonar. La incidencia de afectación del sistema nervioso central (SNC) es baja ${ }^{1}$. La panarteritis nudosa clásica afecta el SNC hasta en un $23 \% \%^{2}$ y habitualmente se presenta como un aneurisma intracerebral. El tratamiento habitual son los corticoides y se asocia ciclofosfamida si se afecta el riñón. Otros citotóxicos como la azatioprina se utilizan para mantener la remisión clínica ${ }^{3}$.

En nuestro caso podemos ver tres peculiaridades que lo hacen excepcional: en primer lugar; la afectación del SNC con arteriografía que no mostró la presencia de aneurismas intracerebrales, en segundo lugar; la bacteriemia y ventriculitis precoz por Salmonella enteritidis, dado que la salmonellosis extraintestinal afecta a distintos tejidos siendo las infecciones focales intracraneales manifestaciones poco frecuentes ${ }^{4}$ y en tercer lugar, el hecho que a pesar de que Salmonella enteritidis siempre estuvo correctamente cubierta, únicamente mejoró tras el inicio de antibioterapia por vía endovenosa, por vía lumbar e intratecal con amikacina ${ }^{5}$, lo cual hace sospechar que pudo existir compartimentalización entre el espacio supra e infratentorial.

P. VERA ARTAZCOZ, A. BETBESE ROIG E I. MORÁN CHORRO

Servicio de Medicina Intensiva. Hospital Santa Creu i Sant Pau. Barcelona. España.

\section{BIBLIOGRAFÍA}

1. Guillevin L, Durand-Gasselin B, Cevallos R, Gayraud M, Lhote F, Callard P, et al. Microscopic polyangiitis: clinical and laboratory findings in eighty-five patients. Arthritis Rheum. 1999; 42:421-30.

2. Cupps TR. Fauci AS. The vasculitides. En: Smith LH, editor. Major problems in Internal Medicine. Philadelphia: WB Saunders; 1981. p. 29-41.

3. Venetz JP, Rossert J. Microscopic polyangiitis Ann Med Interne (Paris). 2000;151:193-8.

4. Rodríguez RE, Valero V, Watanakunakorn C. Salmonella focal intracranial infections: review of the world literature (18841984) and report of an unusual case. Rev Infect Dis. 1986;8:3141.

5. Gilbert VE, Beals JD Jr, Natelson SE, Tyler WA. Treatment of cerebroespinal fluids leaks and gram-negative bacillary meningitis with large doses of intrathecal amikacin systemic antibiotics. Neurosurgery. 1986;18:402-6. 